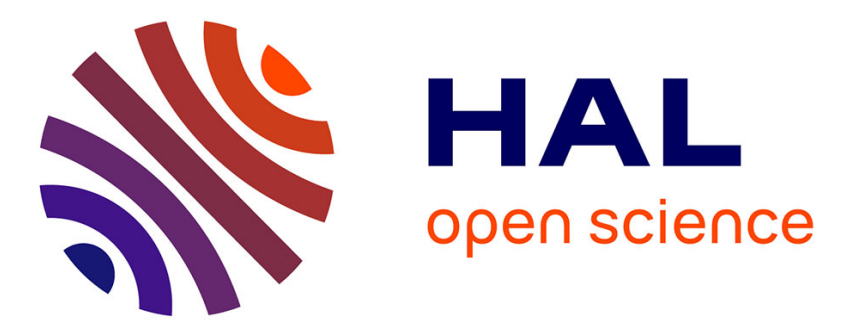

\title{
Validation of BdCCp2 as a marker for Babesia divergens sexual stages in ticks
}

\author{
Claire Becker, Laurence Malandrin, Thibaut T. Larcher, Alain Chauvin, \\ Emmanuel Bischoff, Sarah Bonnet
}

\section{> To cite this version:}

Claire Becker, Laurence Malandrin, Thibaut T. Larcher, Alain Chauvin, Emmanuel Bischoff, et al.. Validation of BdCCp2 as a marker for Babesia divergens sexual stages in ticks. Experimental Parasitology, 2013, 133 (1), pp.51-56. 10.1016/j.exppara.2012.10.007 . hal-02642668

\section{HAL Id: hal-02642668 \\ https://hal.inrae.fr/hal-02642668}

Submitted on 28 May 2020

HAL is a multi-disciplinary open access archive for the deposit and dissemination of scientific research documents, whether they are published or not. The documents may come from teaching and research institutions in France or abroad, or from public or private research centers.
L'archive ouverte pluridisciplinaire HAL, est destinée au dépôt et à la diffusion de documents scientifiques de niveau recherche, publiés ou non, émanant des établissements d'enseignement et de recherche français ou étrangers, des laboratoires publics ou privés. 


\title{
Validation of BdCCp2 as a marker for Babesia divergens sexual stages in ticks
}

\author{
Claire A.M. Becker ${ }^{\mathrm{a}, 1}$, Laurence Malandrin ${ }^{\mathrm{a}}$, Thibaut Larcher $^{\mathrm{b}}$, Alain Chauvin ${ }^{\mathrm{a}}$, Emmanuel Bischoff ${ }^{\mathrm{c}, 2}$, \\ Sarah I. Bonnet ${ }^{\mathrm{a}, *}$ \\ a UMR INRA ONIRIS 1300 BioEpAR, Nantes, France \\ ${ }^{\mathrm{b}}$ UMR INRA ONIRIS 703 APEX, Nantes, France \\ ${ }^{\mathrm{c}}$ Institut Pasteur, Plateforme Puce à ADN PF2, Paris, France
}

\section{H I G H L I G H T S}

- We produced antisera to detect Babesia divergens BdCCp2 protein.

- Protein was never detected in red blood cells parasite population.

- BdCCp2 protein was detected in infected tick guts by Western blot.

- We visualized marked forms inside infected tick guts by immunohistochemistry.

- We produced tools to monitor $B$. divergens transmission.

\section{A R T I C L E I N F O}

\section{Article history:}

Received 16 March 2012

Received in revised form 9 October 2012

Accepted 12 October 2012

Available online 24 October 2012

\section{Keywords:}

Babesia divergens

Ixodes ricinus

Gametocytes

Transmission

Molecular marker
G R A P H I C A L A B S T R A C T

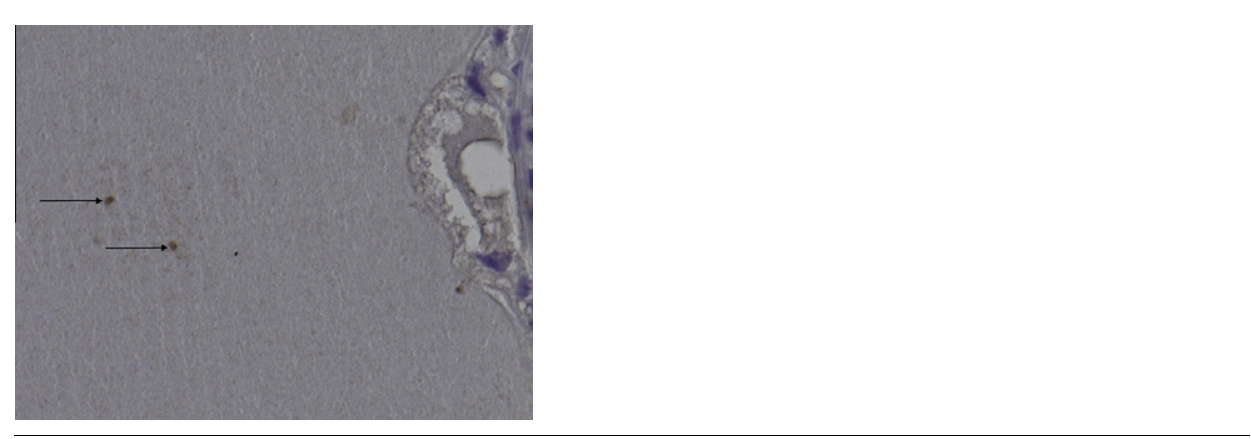

\begin{abstract}
A B S T R A C T
Babesiosis is a tick-transmitted disease of mammalian hosts, caused by the intraerythrocytic protozoan parasites of the genus Babesia. Transmission of Babesia parasites from the vertebrate host to the tick is mediated by sexual stages, the gametocytes which are the only intraerythrocytic stages that survive and develop inside the vector. Very few data are available concerning these parasite stages and some markers are needed in order to refine our knowledge of Babesia life cycle inside the tick and to permit the monitoring of parasite transmission from vertebrate to vector. We previously identified some potential markers of the Babesia divergens gametocytes using an in silico post-genomic approach based on sequence identity between the available genomes of Plasmodium and Babesia spp. Here, one of the identified proteins, BdCCp2, was validated as a marker of sexual stages of $B$. divergens, in infected ticks challenged with antisera directed against recombinant BdCCp2 protein. The BdCCp2 protein was detected by Western blot in some infected ticks, as a discrete band of approximately $171 \mathrm{kDa}$, while no signal was detected in the laboratory-reared non-infected tick. BdCCp2 was also detected, by immunohistochemical analyses, in piriform or ovoid bodies, measuring 2.5-4.5 $\mu \mathrm{m}$ in diameter, in the gut of partially engorged ticks that were experimentally infected. This molecular marker can then be used in the future to characterize and analyze the biology of $B$. divergens gametocytes.
\end{abstract}

(c) 2012 Elsevier Inc. All rights reserved.

\footnotetext{
* Corresponding author. Address: USC INRA Bartonella-tiques, ANSES, 23 rue du Général de Gaulle, 94706 Maisons-Alfort cedex, France. Fax: +33 0149772828. E-mail address: sbonnet@vet-alfort.fr (S.I. Bonnet).

1 Present address: Université de Lyon, VetAgro Sup, UMR Mycoplasmoses des Ruminants Anses VetAgro Sup, F-69280, Marcy l'Etoile, France.

2 Present address: Unité de génétique et génomique des insectes vecteurs, Institut Pasteur, Paris, France.
}

\section{Introduction}

Babesiosis is a worldwide disease due to intraerythrocytic protozoan parasites from the genus Babesia. It is known as a source of emerging zoonosis and its public health impact on livestock and humans is ongoing (Genchi, 2007; Gray et al., 2010; Vannier and Krause, 2009). The disease causes principally fever and anemia but also hemoglobinuria, hyperbilirubinuria, and possibly organ 
failure (Homer et al., 2000). Babesia parasites are transmitted to the mammalian host by ticks. In Europe, Babesia divergens is the most frequent species infecting domestic cattle (Zintl et al., 2003) and is transmitted by the hard tick Ixodes ricinus. This bovine parasite is also thought to be responsible for most European cases of human babesiosis (Häselbarth et al., 2007; Martinot et al., 2011). Some cases of human babesiosis attributed to other Babesia species, namely Babesia sp. EU1 (Häselbarth et al., 2007; Herwaldt et al., 2003) and Babesia microti (Hildebrandt et al., 2007), have been recently reported.

Very few data are available concerning the life cycle of Babesia and its sexual reproduction inside the tick vector. In fact, only asexual reproduction within the salivary glands of vector ticks and within the blood cell of vertebrates have been identified with certainty (Mehlhorn and Schein, 1984). When a tick feeds on an infected vertebrate, where the parasite multiplies by binary asexual division in red blood cells, it can acquire some piroplasms in its blood meal. Inside the tick, only parasite sexual stages, the gametocytes, survive and evolve to different steps of development: gamogony and sporogonies in various tick organs (Mehlhorn and Schein, 1984). The first step of this development is the sexual reproduction inside the tick gut, which involves male and female gametocytes. Gametocytes were discovered for Babesia bigemina by Koch in 1906 and were called Strahlenkörper (ray bodies) (Koch, 1906). After that, they were described for different Babesia species inside ticks (Friedhoff and Buscher, 1976; Karakashian et al., 1983; Mehlhorn et al., 1980). More recently B. bigemina sexual stages could be in vitro produced in red blood cells without tick antigen and were isolated without the use of specific markers (Mosqueda et al., 2004; Vichido et al., 2008). Concerning B. divergens, only two studies report the visualization of potential sexual stages inside the tick gut (Bonnet et al., 2007; Mackenstedt et al., 1990). Some markers permitting the identification of gametocytes with certainty are needed to refine knowledge on such stages and moreover to investigate the mechanisms that control parasite transmission as well as the relationships between parasites and tick vectors.

We previously identified three B. divergens genes ( bdccp1, bdccp2 and bdccp3) thanks to a post-genomic bioinformatics analysis based on sequence identity between the available genomes of Plasmodium spp. and Babesia spp. (Becker et al., 2010). The 3 genes are orthologs of Plasmodium genes that are sexual stage specific and belong to the well-conserved Apicomplexan CCp (Limulus Coagulation factor $\mathrm{C}$ domain proteins) family. Antibodies were produced against one of these proteins, BdCCp2, to further study protein expression. Tested on Plasmodium berghei gametocytes, the results showed that these antibodies specifically recognized hemoprotozoan gametocytes and not parasite asexual stages. In the present study, these antibodies were used to validate their ability to specifically recognize tick-specific parasite stages among which are necessarily the sexual stages of $B$. divergens and subsequently, the capacity of BdCCp2 to be used as a marker of $B$. divergens gametocytes.

\section{Material and methods}

\subsection{Parasite culture}

B. divergens (Bob2A clone) was cultured in bovine red blood cells in Roswell Park Memorial Institute 1640 medium (Lonza, Basel, Switzerland) and 20\% Fetal Calf Serum (Lonza, Basel, Switzerland) as previously described (Chauvin et al., 2002), until $10 \%$ parasitemia was attained. The bovine blood used in all experiments was obtained from parasite-free cows (tested by culture) reared at the Ecole Nationale Vétérinaire de Nantes.

\subsection{Ticks}

Parasite-free I. ricinus females, reared in the laboratory, were artificially engorged and infected with a parasite culture using an in vitro feeding system as previously described (Bonnet et al., 2007), and used for immunohistochemistry analysis. Ticks engorged with non-infected blood were used as negative controls. In addition, partially engorged ticks were collected on cows in a farm where the presence of $B$. divergens had been previously attested (56\% of cows positive by IFA-Immunofluorescence Antibody Assay) (La Verrie, France) (Becker et al., 2009). The serological status of the cows was evaluated and, on the whole sampling, 17 ticks collected on 9 seropositive cows and 17 others collected on 9 seronegative cows were studied (Table 1 ).

\subsection{BdCCp2 recombinant polypeptides synthesis and antisera production}

Two different antisera, directed against the same BdCCp2 region, were produced in parallel as previously described and were validated as able to recognize $P$. berghei gametocytes (Becker et al., 2010).

Briefly, a recombinant polypeptide of 284 amino acids named rpBdCCp2 and based on the BdCCp2 sequence was produced in bacteria, and used to generate a specific immune serum ( $\mathrm{R}$ serum) by subcutaneous immunization of a rabbit (Charles River Laboratories, L'Arbresle, France). A 15 amino acids synthetic peptide, included in the rpBdCCp2 sequence (Eurogentec, Seraing, Belgium) designated spBdCCp2, and based on the P. falciparum PfCCp2 immunogenic peptide (Pradel et al., 2004; Pradel et al., 2006), was also used to generate guinea pig antiserum (G serum) by the Eurogentec company ("Super speedy 28 day polyclonal antibody production"). Here both sera were used for the detection of sexual stages of $B$. divergens both by immunoblot and immunohistochemistry analysis.

\subsection{Immunohistochemistry analysis}

Five partially engorged female ticks, 3 experimentally infected by membrane feeding technique and 2 non-infected negative controls, were fixed, in their entirety, for $48 \mathrm{~h}$ in $10 \%$ neutral buffered formalin and embedded in paraffin wax. For immunohistochemical analyses, $4 \mu \mathrm{m}$ thick sections were cut, dewaxed and pretreated for 6 min with trypsin $\left(1 \mathrm{mg} / \mathrm{ml}\right.$ ) (Sigma) at $37^{\circ} \mathrm{C}$ and in $3 \%$ hydrogen peroxide (Gifrer, Decines, France) for $10 \mathrm{~min}$ at room temperature. Sections were then blocked for 20 min with $20 \%$ normal goat serum (Dako, Glostrup, Denmark).

$\mathrm{R}$ and $\mathrm{G}$ sera, diluted at 1:500 and 1:10 respectively, were used as primary antibodies and incubated on slides in $2 \%$ Bovine Serum Albumin (Sigma) for $1 \mathrm{~h}$ at $37^{\circ} \mathrm{C}$. Corresponding pre-immune sera were used as negative controls. The slides were then incubated with anti-rabbit (Dako) or anti-guinea pig (Jackson Immunoresearch Laboratories) biotinylated secondary antibodies in $2 \%$ Bovine Serum Albumin for $30 \mathrm{~min}$ and revealed with streptavidin (Dako) and DAB Liquid Substrate for immunoperoxidase (Dako), according to the manufacturer's instructions. The slides were counterstained with Gill's hematoxylin (Surgipath, Peterborough, UK) and examined under a microscope.

\subsection{SDS-PAGE and immunoblot analysis}

Immune sera were tested on in vitro cultures of $B$. divergens parasites and on gut contents of ticks collected on cows. The thirtyfour field-collected ticks and one non-infected control tick were dissected in a small drop of PBS (Phosphate Buffered Saline) and the tick guts were frozen at $-20^{\circ} \mathrm{C}$ until use. Protease Inhibitor 
Table 1

BdCCp2 protein detection by Western blot in I. ricinus ticks collected on cows from a $B$. divergens infected cow herd. The serological status of cows was evaluated by Immunofluorescence Antibody Assay against B. divergens antigens.

\begin{tabular}{llc}
\hline $\begin{array}{l}\text { Cow serological status } \\
\text { (number of cows) }\end{array}$ & \multicolumn{2}{l}{ Western blot result (number of ticks) } \\
\cline { 2 - 3 } Total (34) & Protein detected $(8)$ & No signal $(26)$ \\
\hline$+(17)$ & 8 & 9 \\
$-(17)$ & 0 & 17 \\
\hline
\end{tabular}

Cocktail (Sigma) was added to all samples ( $3 \mu \mathrm{l}$ for $250 \mu \mathrm{l}$ of sample) just before freezing.

Individual tick guts and parasite culture samples $(250 \mu \mathrm{l})$ were washed with $1 \mathrm{ml}$ of PBS, lysed with $1 \mathrm{ml}$ of $0.01 \%$ saponin (Sigma) at room temperature, and washed 3 times with $1 \mathrm{ml}$ of PBS. Pellets were treated for $5 \mathrm{~min}$ at $100{ }^{\circ} \mathrm{C}$ with SDS-PAGE Sample Buffer (v/ v) (Tris- $\mathrm{HCl} 62.5 \mathrm{mmol} / \mathrm{l}$, Glycerol $10 \%$, ß-mercaptoethanol $2 \%$, Bromophenol Blue $0.1 \%$, SDS $2 \%$ ), centrifuged for $30 \mathrm{~s}$ and $20 \mu \mathrm{l}$ of the collected supernatant was analyzed on a $8 \%$ acrylamide SDS-PAGE (Sodium Dodecyl Sulfate PolyAcrylamide Gel Electrophoresis) gel under reducing conditions. The proteins were then transferred ( $3 \mathrm{~h}$ at $50 \mathrm{~mA}$ ) onto a nitrocellulose membrane (BioRad) with a TG powder buffer (Interchim, Montluçon, France). After a saturation step of $30 \mathrm{~min}$ with Tris buffered saline and $0.1 \%$ Tween-20 (Sigma) (TBSt) containing 10\% non-fat milk, the membrane was incubated with G serum $(1: 250)$ for 30 min in TBSt milk $5 \%$. After washing, the membranes were incubated for $30 \mathrm{~min}$ with Alkaline Phosphatase-conjugated AffiniPure Goat Anti-Guinea Pig IgG (Jackson ImmunoResearch Laboratories, Newmarket, UK), diluted 1:10,000 in TBSt milk $5 \%$ and developed in a solution of 5Bromo-4-chloro-3-indolyl phosphate and nitro-blue tetrazolium chloride (BCIP ${ }^{\circledR} / \mathrm{NBT}$, Sigma).

\subsection{Ethics statement}

This study was carried out in strict accordance with the good animal care practice of the recommendations of the European guidelines. The protocol was approved by the Committee on the Ethics of Animal Experiments of the national Veterinary School of Nantes and all efforts were made to minimize suffering of animals.

\section{Results}

3.1. Detection of $B$. divergens sexual stages by immunohistochemistry on artificially infected ticks

Immunohistochemical analyses were performed with $\mathrm{R}$ and $\mathrm{G}$ sera on partially engorged ticks that were experimentally infected. The BdCCp2 protein was detected in piriform or ovoid bodies, measuring $2.5-4.5 \mu \mathrm{m}$ in diameter, in the tick gut (Fig. 1C and D). Similar labeled elements, comparable with previously described sexual stages of Babesia spp., were obtained with both sera (the R serum giving a better signal). Isolated bodies or sometimes clusters of two bodies were scattered in the blood meal. Asexual stages, although largely present in the blood meal (as attested by Giemsa staining of the adjacent serial section of the sample, Fig 1B), were not recognized by the sera. Roughly a dozen labeled organisms were observed in a coronal section of experimentally infected ticks: this low proportion, in relation to the parasite population as a whole, could be consistent with gametocyte frequency. No labeling of the blood meal was obtained for non-infected engorged ticks (Fig. 1E and F) or with non-immune sera on infected engorged tick (Fig. $1 \mathrm{G}$ and $\mathrm{H}$ ).
3.2. Detection of BdCCp2 by immunoblot analysis in B. divergens infected erythrocytes and in naturally infected ticks

Protein samples from the digestive tract of partially engorged ticks collected on cows and from an in vitro culture of $B$. divergens in bovine erythrocytes were run on SDS-PAGE and challenged with G serum by Western blot. Red Ponceau coloration performed before the immunostaining showed that a similar amount of proteins was loaded in each lane (data not shown). Results obtained for the 34 tested ticks are presented in Table 1 . The BdCCp2 protein was detected in 8 naturally infected ticks out of the 34 tested, as a discrete band of approximately $171 \mathrm{kDa}$, whereas no signal was detected in the laboratory-reared non-infected tick (Fig. 2A). It is noticeable that BdCCp2 was only detected inside ticks that engorged on seropositive cows and that among those ticks, signal was not systematically detected (Table 1 ). Furthermore, when ticks were collected on the same cow, some of them gave positive result and other a negative one in Western blot (data not shown). Finally, the BdCCp2 protein was not detected in protein samples from red blood cells infected by $B$. divergens (Fig. 2B).

\section{Discussion}

Babesiosis has been recently considered emerging zoonosis and Babesia spp. correspond to the second most common blood-borne parasites of mammals after the trypanosomes (Häselbarth et al., 2007). Nevertheless, a lot of data are missing concerning the life cycle of these parasites, in particular their acquisition by and their development inside the tick vector. To understand conditions of transmission from vertebrate host to vector, one necessary point is to study and determine the conditions of the gametocytes appearance and the factors that rule their acquisition by the tick. The characterization of $B$. divergens sexual stages using molecular tools permitting accurate identification of gametocytes is hence essential to study parasite biology and monitor transmission. With this aim in view, we used an in silico post-genomic approach in a previous work, to identify genes that are sexual stage specific in $B$. divergens (Becker et al., 2010). Three genes bdccp1, bdccp2 and bdccp 3 were identified and the mRNA of these 3 genes were detected in the intraerythrocytic parasite population (Becker et al., 2010 ). Such results suggested that the $B$. divergens population inside the vertebrate host is already committed to the sexual pathway, as reported for Plasmodium genus (Lavazec et al., 2009; Pradel et al., 2004). Bdccp genes, specific of gametocytes, could then be used as molecular markers, through the detection of their mRNA, to evaluate the production of sexual stages in the vertebrate host (Becker et al., 2010). We previously produced antisera directed against a recombinant peptide of one of the identified proteins, BdCCp2. As the gametocytes of $B$. divergens have not be isolated to date, the absence of possible positive control forced us to validate this protein as a marker of hemoprotozoan gametocytes, since the antisera recognized the intraerythrocytic sexual stages of $P$. berghei (Becker et al., 2010). In the present work our aim was to evaluate the specificity of these antisera for $B$. divergens gametocytes and thus, the possibility to use BdCCp2 as a marker for parasite sexual stages.

Immunohistochemistry analysis revealed that a few parasites, similar in size to the sexual stages of other Babesia spp. (Friedhoff and Buscher, 1976; Mehlhorn et al., 1980; Mosqueda et al., 2004; Rudzinska et al., 1979), were marked by anti-BdCCp2 sera, within the tick gut. These labeled elements confirm the existence of $B$. divergens sexual stages inside the tick as already suggested both by DNA measurements (Mackenstedt et al., 1990) and microscopical observations (Bonnet et al., 2007). Yet it is currently impossible to determine whether these marked parasites are $B$. divergens gametocytes just after their arrival in the tick, gametes just before 

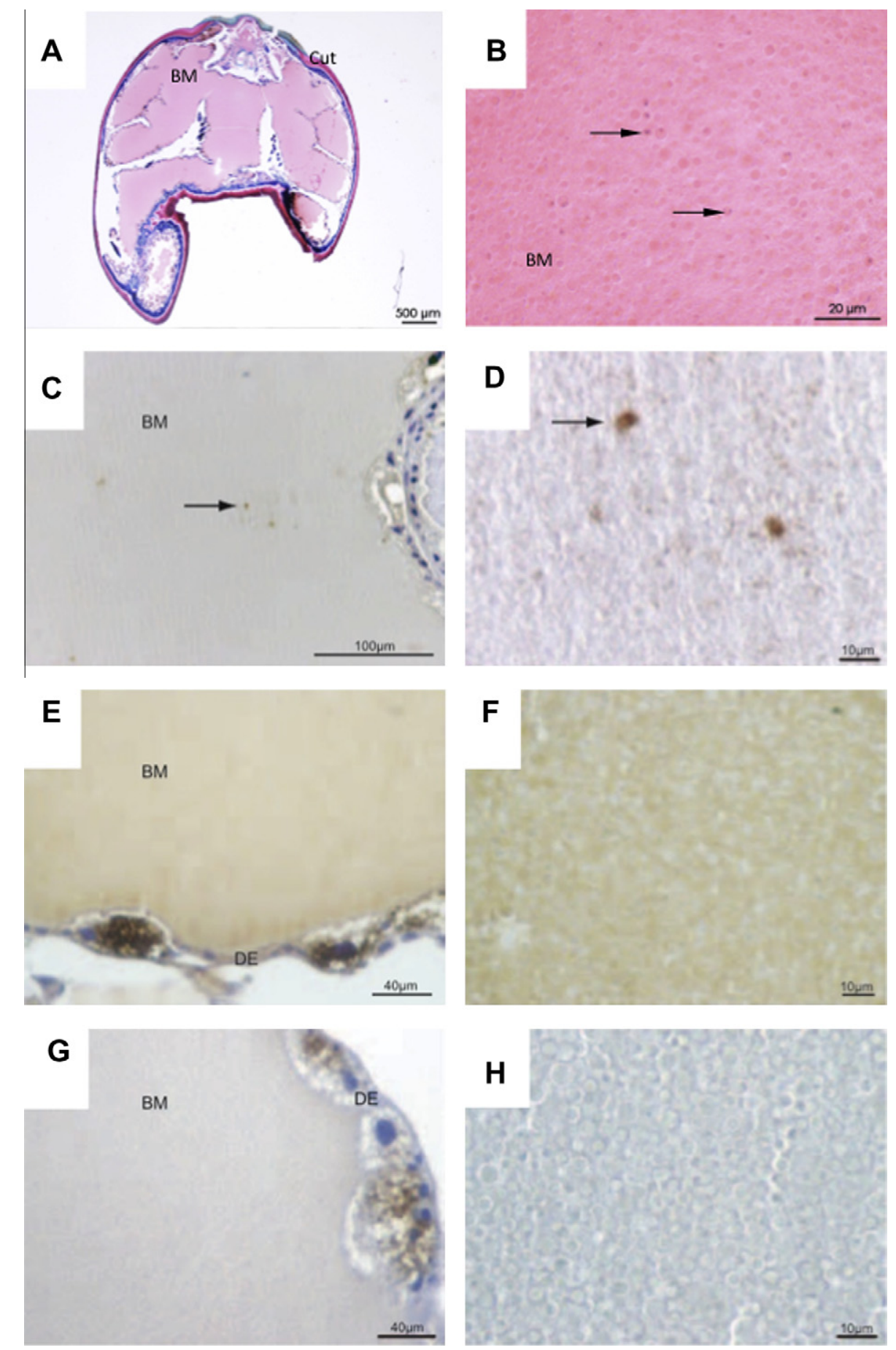

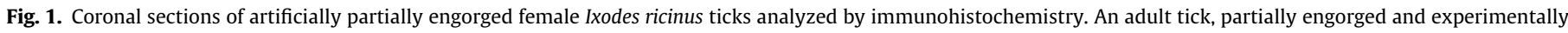

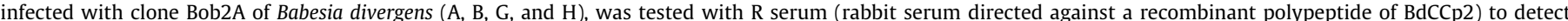

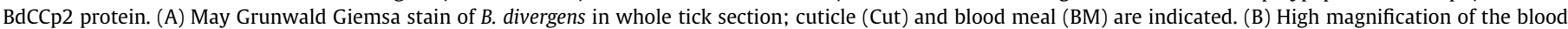

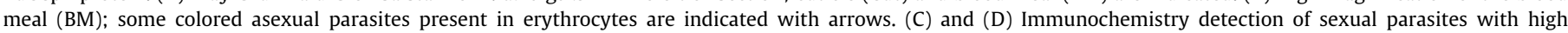

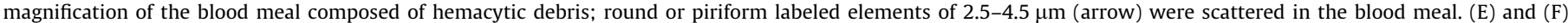

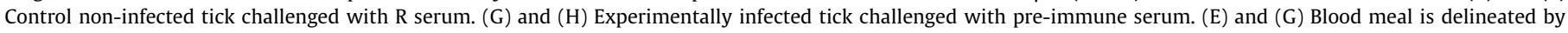

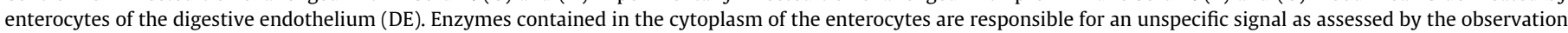
that a similar signal was present on experimentally infected tick challenged without primary and secondary antibodies.

fusion, or zygotes. IFA, another method that should permit to observe parasites with a finer resolution, was tested but a too high background due to tick gut content prevented us to visualize parasites (data not shown). Thus, our results confirm that the BdCCp2 protein is expressed by a minute part of $B$. divergens parasites inside the tick and can be used there as a marker of $B$. divergens sexual stages.
The protein BdCCp2 was not detected in intraerythrocytic stages of $B$. divergens, neither by Western blot nor by IFA (data not shown) on infected bovine erythrocytes, showing that, in vitro, the protein was not expressed in the $B$. divergens asexual population. In contrast, BdCCp2 was detected inside $B$. divergens infected ticks, either artificially from in vitro culture or naturally engorged. Western blot analysis showed, in naturally engorged ticks, a band 

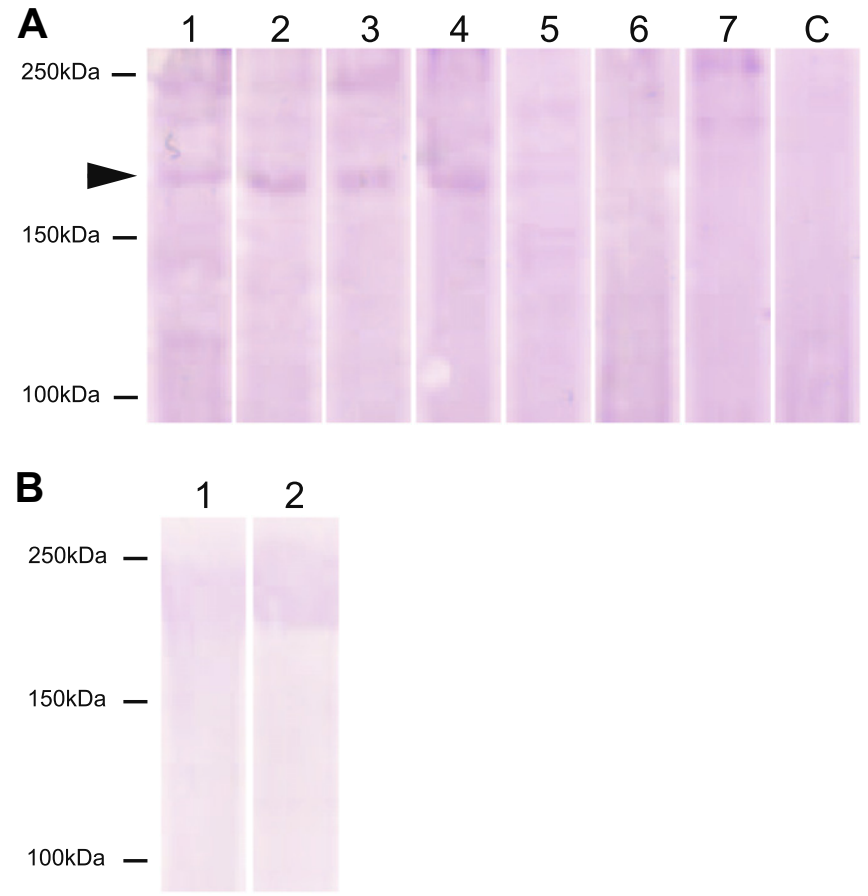

Fig. 2. BdCCp2 detection by Immunoblot analysis of gut contents of partially engorged $I$. ricinus fed on $B$. divergens seropositive cows (A) and red blood cell populations (B). Protein extracts were challenged with $G$ serum (guinea pig serum directed against a synthetic peptide of BdCCp2, spBdCCp2). (A) Lanes 1-7: gut content extract of some ticks engorged on serologically positive cows. Ticks 1-5 give a positive result when tick 6 and 7 give a negative one. Lane C: gut content extract from a negative control tick. The band corresponding to BdCCp2 (around $171 \mathrm{kDa}$ ) is indicated by an arrow. Double band around $200 \mathrm{kDa}$ corresponds to non-specific reactions against red blood cell proteins. (B) Lane 1: non-infected bovine erythrocytes; Lane 2: B. divergens (clone Bob2A) in vitro infected bovine erythrocytes. No positive signal is observed.

at $171 \mathrm{kDa}$, the molecular weight estimated for BdCCp2 (Becker et al., 2010). Low signal strength was probably due to the very small amount of BdCCp2 protein that is present inside whole tick gut protein extract, sexual stages being only a minute part of the parasite population. In addition to get a signal on the blot, we had to incubate nitrocellulose membrane with the substrate for about 15 min, explaining the high level of background. Nonetheless, our assay revealed the presence of BdCCp2 in only 8 out of the 34 ticks tested, and only among the 17 ticks that were collected on seropositive cows. That could be explained by the fact that except at the onset of infection, seronegative cows usually do not carry $B$. divergens, leading in most cases to parasite-free engorged ticks. In contrast, not all the ticks that fed on seropositive cows showed BdCCp2 signal. Even if a previous study indicated a good correlation (89.6\%) between a positive serological status and intraerythrocytic asymptomatic carriage detected by in vitro culture (Malandrin et al., 2004), the frequency of gametocytes should be even lower compared to that of asexual stages and these forms may not be present in the blood meal ingested by the tick. It is noticeable that two ticks collected on the same seropositive cow did not show the same result. The presence of negative and positive ticks collected from the same cow indicates either that transmission to the tick is not always effective or that the low amount of transmitted gametocytes is not systematically detectable with our method. Moreover some cows fed ticks that were all detected positive whereas others cows only gave negative ticks. It could have been interesting to test the production of sexual stages by searching the presence of $b d c c p 2$ mRNA in cow blood.

Finally there is apparently a discrepancy between the times of transcription and translation of this gene. As we could show in a previous publication (Becker et al., 2010) bdccp2 is transcribed but not translated to a protein in the vertebrate host. In the present work we could detect the protein only inside the vector. This could be explained by the fact that the parasite population might be already committed to the sexual pathway inside the vertebrate host but might only express sexual stage proteins under specific conditions that are only encountered inside the vector. It is then concomitant with the morphological transformation observed only once in the tick for other Babesia species (Mehlhorn and Schein, 1984; Smith et al., 2002). The functions of B. divergens BdCCp2 protein need to be further studied and established. As BdCCp2 contains adhesive domains, like all the members of the apicomplexan CCp family (Becker et al., 2010; Dessens et al., 2004), it might be involved in specific events happening only inside the tick, such as adhesion of gametes, as it is reported for Plasmodium spp. (Kuehn et al., 2010; Simon et al., 2009).

\section{Conclusion}

We confirmed the existence of $B$. divergens sexual stages inside the vector tick I. ricinus. We also showed that transmission of $B$. divergens from cow to tick cannot be considered fully efficient at the tick population level, even if all required conditions are present. Our investigations permitted development of tools that will be very useful to study $B$. divergens biology. Thanks to our molecular markers, methods could be developed to quantitatively monitor the sexual stages of this parasite inside the vertebrate host and to follow the parasites inside the vector. These tools may be used in epidemiological studies in order to characterize and quantify parasite transmission. Understanding the parameters that govern the transmission of Babesia from the vertebrate host to the tick, should help explain the appearance of the clinical cases of babesiosis and pave the way to novel approaches of disease control.

\section{Acknowledgments}

We are grateful to Maggy Jouglin (INRA), Agnès Bouju-Albert (ENVN), Béatrice Oberhauser (ENVN) and Lydie Guigand (ENVN) for technical assistance, to Peter H. David (Institut Pasteur) for helpful discussions and English corrections and to the "Tiques et Maladies à Tiques" group (REID-Réseau Ecologie des Interactions Durables) for stimulating discussions. This work is part of CB's $\mathrm{PhD}$ thesis, which was funded by INRA and Region Pays de Loire. EB was funded by the Délégation Générale pour l'Armement (DGA n 22120/DSP/SREAF and n 0434 025).

\section{References}

Becker, C.A.M., Bouju-Albert, A., Jouglin, M., Chauvin, A., Malandrin, L., 2009. Natural transmission of zoonotic Babesia spp. by Ixodes ricinus ticks. Emerg. Infect. Dis. $15,320-322$.

Becker, C.A.M., Malandrin, L., Depoix, D., Larcher, T., David, P.H., Chauvin, A., Bischoff, E., Bonnet, S., 2010. Identification of three CCp genes in Babesia divergens: novel markers for sexual stages parasites. Mol. Biochem. Parasitol. 174, 36-43.

Bonnet, S, Jouglin, M., Malandrin, L., Becker, C., Agoulon, A. L'Hostis, M., Chauvin, A. 2007. Transstadial and transovarial persistence of Babesia divergens DNA in Ixodes ricinus ticks fed on infected blood in a new skin-feeding technique. Parasitology 134, 197-207.

Chauvin, A., Valentin, A., Malandrin, L., L'Hostis, M., 2002. Sheep as a new experimental host for Babesia divergens. Vet. Res. 33, 429-433.

Dessens, J.T., Sinden, R.E., Claudianos, C., 2004. LCCL proteins of apicomplexan parasites. Trends Parasitol. 20, 102-108.

Friedhoff, K.T., Buscher, G., 1976. Rediscovery of Koch's "Strahlenkörper" of Babesia bigemina. Z. Parasitenkd. 50, 345-347.

Genchi, C., 2007. Human babesiosis, an emerging zoonosis. Parassitologia 49, 29-31.

Gray, J., Zintl, A., Hildebrandt, A., Hunfeld, K.P., Weiss, L., 2010. Zoonotic babesiosis: overview of the disease and novel aspects of pathogen identity. Ticks Tick Borne Dis. 1, 3-10. 
Häselbarth, K., Tenter, A.M., Brade, V., Krieger, G., Hunfeld, K.P., 2007. First case of human babesiosis in Germany - Clinical presentation and molecular characterisation of the pathogen. Int. J. Med. Microbiol. 297, 197-204.

Herwaldt, B.L., Caccio, S., Gherlinzoni, F., Aspock, H., Slemenda, S.B., Piccaluga, P., Martinelli, G., Edelhofer, R., Hollenstein, U., Poletti, G., Pampiglione, S. Loschenberger, K., Tura, S., Pieniazek, N.J., 2003. Molecular characterization of a non-Babesia divergens organism causing zoonotic babesiosis in Europe. Emerg. Infect. Dis. 9, 942-948.

Hildebrandt, A., Hunfeld, K.P., Baier, M., Krumbholz, A., Sachse, S., Lorenzen, T., Kiehntopf, M., Fricke, H.J., Straube, E., 2007. First confirmed autochthonous case of human Babesia microti infection in Europe. Eur. J. Clin. Microbiol. Infect. Dis. 26, 595-601.

Homer, M.J., Aguilar-Delfin, I., Telford 3rd, S.R., Krause, P.J., Persing, D.H., 2000. Babesiosis. Clin. Microbiol. Rev. 13, 451-469.

Karakashian, S.J., Rudzinska, M.A., Spielman, A., Lewengrub, S., Piesman, J. Shoukrey, N., 1983. Ultrastructural studies on sporogony of Babesia microti in salivary gland cells of the tick Ixodes dammini. Cell Tissue Res. 231, 275-287.

Koch, R., 1906. Beiträge zur Entwicklungsgeschichte der Piroplasmen. Z. Hyg. Infektionskr. 54, 1-9.

Kuehn, A., Simon, N., Pradel, G., 2010. Family members stick together: multi-protein complexes of malaria parasites. Med. Microbiol. Immunol. (Berlin) 199, 209226.

Lavazec, C., Moreira, C.K., Mair, G.R., Waters, A.P., Janse, C.J., Templeton, T.J., 2009. Analysis of mutant Plasmodium berghei parasites lacking expression of multiple PbCCp genes. Mol. Biochem. Parasitol. 163, 1-7.

Mackenstedt, U., Gauer, M., Mehlhorn, H., Schein, E., Hauschild, S., 1990. Sexual cycle of Babesia divergens confirmed by DNA measurements. Parasitol. Res. 76, 199-206.

Malandrin, L., L'Hostis, M., Chauvin, A., 2004. Isolation of Babesia divergens from carrier cattle blood using in vitro culture. Vet. Res. 35, 131-139.

Martinot, M., Zadeh, M.M., Hansmann, Y., Grawey, I., Christmann, D., Aguillon, S., Jouglin, M., Chauvin, A., De Briel, D., 2011. Babesiosis in immunocompetent patients, Europe. Emerg. Infect. Dis. 17, 114-116.
Mehlhorn, H., Schein, E., 1984. The piroplasms: life cycle and sexual stages. Adv. Parasitol. 23, 37-103.

Mehlhorn, H., Schein, E., Voigt, W.P., 1980. Light and electron microscopic study on developmental stages of Babesia canis within the gut of the tick Dermacentor reticulatus. J. Parasitol. 66, 220-228.

Mosqueda, J., Falcon, A., Antonio Alvarez, J., Alberto Ramos, J., Oropeza-Hernandez, L.F., Figueroa, J.V., 2004. Babesia bigemina sexual stages are induced in vitro and are specifically recognized by antibodies in the midgut of infected Boophilus microplus ticks. Int. J. Parasitol. 34, 1229-1236.

Pradel, G., Hayton, K., Aravind, L., Iyer, L.M., Abrahamsen, M.S., Bonawitz, A., Mejia C., Templeton, T.J., 2004. A multidomain adhesion protein family expressed in Plasmodium falciparum is essential for transmission to the mosquito. J. Exp. Med. 199, 1533-1544.

Pradel, G., Wagner, C., Mejia, C., Templeton, T.J., 2006. Plasmodium falciparum: codependent expression and co-localization of the PfCCp multi-adhesion domain proteins. Exp. Parasitol. 112, 263-268.

Rudzinska, M.A., Spielman, A., Riek, R.F., Lewengrub, S.J., Piesman, J., 1979 Intraerythrocytic 'gametocytes' of Babesia microti and their maturation in ticks. Can. J. Zool. 57, 424-434.

Simon, N., Scholz, S.M., Moreira, C.K., Templeton, T.J., Kuehn, A., Dude, M.A., Pradel, G., 2009. Sexual stage adhesion proteins form multi-protein complexes in the malaria parasite Plasmodium falciparum. J. Biol. Chem. 284, 14537-14546.

Smith, T.G., Walliker, D., Ranford-Cartwright, L.C., 2002. Sexual differentiation and sex determination in the Apicomplexa. Trends Parasitol. 18, 315-323.

Vannier, E., Krause, P.J., 2009. Update on babesiosis. Interdiscip. Perspect. Infect. Dis. 2009, 984568.

Vichido, R., Falcon, A., Ramos, J.A., Alvarez, A., Figueroa, J.V., Norimine, J., Brown W.C., Castro, L.A., Mosqueda, J., 2008. Expression analysis of heat shock protein 20 and rhoptry-associated protein 1a in sexual stages and kinetes of Babesia bigemina. Ann. N. Y. Acad. Sci. 1149, 136-140.

Zintl, A., Mulcahy, G., Skerrett, H.E., Taylor, S.M., Gray, J.S., 2003. Babesia divergens, a bovine blood parasite of veterinary and zoonotic importance. Clin. Microbiol. Rev. 16, 622-636. 